\title{
Advocacy groups continue to scorn screening guidelines
}

A national task force underestimated the benefits of early mammograms while overstating the harms when it recommended the scuttling of routine breast screening of women under the age of 50, breast cancer advocacy groups say.

Excluding "average risk" women aged 40-49 from Ontario's Breast Screening Program is "unfair and inequitable" when such screening is routine in other provinces and backed by "strong scientific evidence and public demand," the Canadian Breast Cancer Foundation - Ontario Region states in a petition, which has already drawn 3200 signatures, to Ontario Minister of Health and Long-Term Care Deb Matthews (www.cbcfscreeningsaves.ca).

The Canadian Task Force on Preventive Health Care issued guidelines in 2011 recommending against routine screening of women in that age group on the grounds that the "harms and costs of false-positive results, overdiagnosis and overtreatment" outweigh the benefits (www.cmaj.ca/lookup/doi/10 .1503/cmaj.110334).

Proponents of the guidelines such as Dr. Walter Rosser, former head of family medicine at Queen's University in Kingston, say the disease spreads so rapidly at younger ages "even early detection doesn't make a huge difference" (www.cmaj.ca/lookup/doi/10.1503 /cmaj.109-4062).

But critics contend that the evidence used to draw that conclusion is dated and fear the recommendations will prove a setback to efforts to expand the "ad hoc" screening of younger women in Ontario.

"The randomized control[led] trials they considered were all between 25 and 40 years old. Mammography screening 25 or 40 years ago was a lot different than it is today. The ability to detect cancer in dense breasts or younger breasts has improved significantly over the years," says Sandra Palmaro, CEO of Canadian Breast Cancer Foundation - Ontario Region. "Since one-in-six women who die from breast cancer

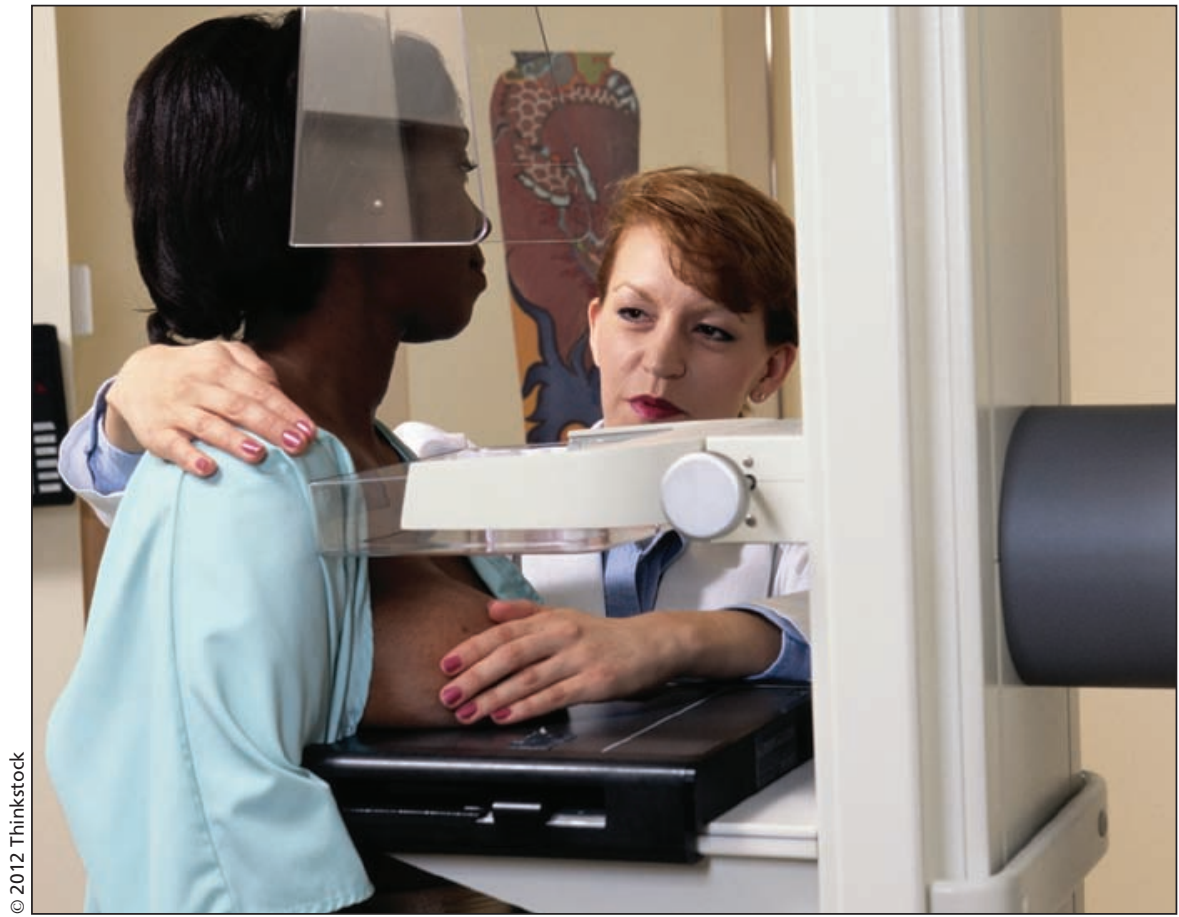

Critics fear new breast cancer screening guidelines will prove a setback to efforts to expand the "ad hoc" screening of younger women in Ontario.

are diagnosed in their 40s, we cannot afford missed opportunities for earlier detection."

They also argue the task force compromised its analysis by including data from the Canadian National Breast Screening Study, which reported a "paradoxical excess of cancer deaths among the screened women" (http://radiology .rsna.org/content/210/1/4.full).

Eight women in that study died of breast cancer within seven years of the trial, as compared to one in the control group, suggesting "corruption of the randomization," says Dr. Paula Gordon, medical director at BC Women's Hospital Breast Health Program. "At the most, if mammography doesn't work, it should be equal. Roll that study in with other trials and it totally skews the results."

The task force also overlooked such benefits as "the fact that when you find a cancer earlier, women need less chemotherapy [and fewer] mastectomies," Gordon adds.
Martin Yaffe, professor of medical biophysics and medical imaging at the University of Toronto in Ontario concurs, noting that the guidelines "almost seem to balance a false-positive mammogram equally against a death averted."

Yaffe also says the task force failed to factor in that women in their forties account for more than $30 \%$ of the years of life lost due to breast cancer.

But Dr. Marcello Tonelli, chair of the task force, counters that the group simply reviewed the randomized controlled trial data that was available, and stands by the decision not to include more recent observational data. "The implication is made that there are newer studies that we're not paying attention to. ... But it's not like there are [randomized controlled trials] that were published more recently. We didn't pick the studies we liked. We looked at all of the studies."

Moreover, he contends the recommendations were not aimed at discouraging women from obtaining mammograms on 
a case-by-case basis once they are aware of the risks and benefits. Instead, they were targeted at encouraging women to "sit down with their doctors and discuss these matters."

The task force argued that routine screening of women aged 40-49 has a higher risk of false-positive results, while prompting unnecessary treatment and anxiety.

"For younger women the benefits are less and the harms are greater," Tonelli explains. "More women in that age group would choose not to be screened if properly informed."

But Ontario patients with breast cancer say that sparing women from false positives, unnecessary treatment and anxiety smacks of paternalism. "It reminds me of arguments about how a woman [should be kept in the dark about her diagnosis because she] might get hysterical," says Laurie Kingston, a woman with metastatic breast cancer who lives in Ottawa, Ontario. "I would much rather be put through the stress I went through when I was waiting to know for sure and then learn there's nothing wrong than find out too late that I had breast cancer."

Kingston also contends the recommendations may make it more difficult for women to obtain mammograms. "I know women in my situation who had to fight for further testing when they had lumps or suspected something was wrong. I was very fortunate that my [general practitioner] took me absolutely seriously right from the beginning but I know that doesn't always happen."
The Canadian Breast Canada Foundation is urging that women aged 40-49 in Ontario, Manitoba, New Brunswick, Newfoundland and Labrador, Quebec and Saskatchewan be allowed to enrol in provincial screening programs for older women, if they have a recommendation from a physician. That's currently how Alberta's program is operated. In British Columbia, Nova Scotia, Prince Edward Island, the Northwest Territories and the Yukon, women under age 50 do not need a physician's stamp of approval to enrol in a provincial screening program. Nunavut has not developed an organized screening program. - Lauren Vogel, CMAJ

CMAJ 2012. DOI:10.1503/cmaj.109-4147 